\title{
The contribution of distinct subregions of the ventromedial frontal cortex to emotion, social behavior, and decision making
}

\author{
P. H. Rudebeck, D. M. BANNERMAN, AND M. F. S. Rushworth \\ University of Oxford, Oxford, England
}

\begin{abstract}
Damage to the ventromedial frontal cortex (VMFC) in humans is associated with deficits in decision making. Decision making, however, often happens while people are interacting with others, where it is important to take the social consequences of a course of action into account. It is well known that VMFC lesions also lead to marked alterations in patients' emotions and ability to interact socially; however, it has not been clear which parts of the VMFC are critical for these changes. Recently, there has been considerable interest in the role of the VMFC in choice behavior during interpersonal exchanges. Here, we highlight recent research that suggests that two areas within or adjacent to the VMFC, the orbitofrontal cortex (OFC) and the anterior cingulate cortex (ACC), may play distinct but complementary roles in mediating normal patterns of emotion and social behavior. Converging lines of evidence from human, macaque, and rat studies now suggest that the OFC may be more specialized for simple emotional responses, such as fear and aggression, through its role in representing primary reinforcement or punishment. By contrast, the ACC may play a distinct role in more complex aspects of emotion, such as social interaction, by virtue of its connections with the discrete parts of the temporal lobe and subcortical structures that control autonomic responses.
\end{abstract}

Psychologists and neuroscientists the world over know the remarkable story of Phineas Gage. While using a tamping iron to push an explosive charge into solid rock, Gage set off an uncontrolled explosion that drove the iron into the left side of his cranium, damaging his ventromedial frontal cortex (VMFC; H. Damasio, Grabowski, Frank, Galaburda, \& Damasio, 1994; Harlow, 1848). Although accidents on the railroad construction sites of 19 th century America were probably common, this case is famous not only because Gage survived, but also because the changes in his personality following the accident were so well documented (Harlow, 1848, 1868). Over the next 12 years until Gage's death, John Harlow recorded the severe changes in decision making and personality that followed the accident (cf. Macmillan, 2002). These records provided the first evidence that a part of the frontal lobe is crucial for preferentially guiding our choices, but also for regulating our emotions and social interactions.

More recently, researchers have been able to further characterize the role of the VMFC in social interaction, emotion, and decision making through work with human patients and animals with damage similar to that suffered by Gage (Bechara, Damasio, \& Damasio, 2000; Murray \& Izquierdo, 2007). From these studies, there has been considerable interest in the contribution of the VMFC to decision making, especially the role of this area in mediating the influence of emotion on decision making (Bechara,
Damasio, Damasio, \& Anderson, 1994; Bechara et al., 2000; Bechara, Damasio, Tranel, \& Damasio, 1997). In their now seminal series of studies, Bechara and colleagues showed that patients with VMFC damage fail to advantageously alter their pattern of choices in a probabilistic game for monetary reward called the Iowa gambling task (IGT; Bechara et al., 1994). Specifically, in comparison with control subjects, patients with VMFC lesions continue to make risky instead of safe choices, even after they have incurred substantial losses. On the basis of additional experiments. it was proposed that patients' disadvantageous pattern of choices may be related to an inability to unconsciously use visceral sensations (somatic markers) to preferentially guide choices (Bechara et al., 1997).

Although it is still acknowledged that VMFC patients perform poorly on a range of decision-making tests $(\mathrm{Ca}-$ mille et al., 2004; Wheeler \& Fellows, 2008), there is now considerable debate concerning the precise role of somatic markers in the patients' decision-making impairments. During the IGT, people with VMFC damage are able to report which are the safe, as opposed to the risky, choices. Such a finding indicates that an inability to unconsciously use somatic markers is not what drives patients' atypical pattern of choices (Maia \& McClelland, 2004). Instead, patients' deficits could be related to an inability to flexibly alter stimulusreward associations (Fellows \& Farah, 2003; Hornak et al., 2004). This explanation is based on findings that VMFC pa- 
tients perform poorly on reversal learning tasks that require subjects to learn stimulus-reward associations and then, subsequently, reverse them. Alternatively, patients' poor performance on the IGT may actually be due to underlying impairments in the making of judgments under uncertainty and the processing of future unseen rewards (Fellows \& Farah, 2007; Moretti, Dragone, \& di Pellegrino, in press).

Decisions, however, are also often made within a social context or while an individual interacts with others. Social factors may influence or bias an individual's choices. Recently, attention has been focused on the role of the VMFC and adjacent but more dorsomedial frontal regions during interpersonal exchanges, using paradigms such as the trust and ultimatum games (King-Casas et al., 2005; Koenigs \& Tranel, 2007; Moretti et al., in press; Rilling et al., 2002; Sanfey, Rilling, Aronson, Nystrom, \& Cohen, 2003; Tomlin et al., 2006). In these paradigms, subjects not only have to make decisions, but also have to take into account the social consequences of those decisions for future dealings (Berg, Dickhaut, \& McCabe, 1995).

Despite this new interest in the role of the VMFC in these types of interpersonal games, one outstanding issue is which parts of this region are important for processing and evaluating social information. The majority of studies have focused on the possibility that damage to one part of the VMFC, the orbitofrontal cortex (OFC; Brodmann areas [BAs] 11,13, and 14), leads to the changes in emotion and social behavior. However, the OFC is only one of three anatomically distinct regions that make up the VMFC in humans, the others being the anterior cingulate cortex (ACC) and the frontal polar cortex (Öngür, Ferry, $\&$ Price, 2003; Figure 1A). Much of our knowledge of the functions of the VMFC has come from humans with lesions centered on this region, but in nearly all of these studies, lesions have included all three areas (Figure 1B). It is important to understand that the term VMFC is not a precise one; it simply refers to tissue that is in the ventromedial part of the frontal lobe. The contribution of these other cortical areas within the VMFC to emotional and social behavior has, by contrast, been relatively overlooked.

There is still uncertainty surrounding the precise functions of the frontal polar cortex (Ramnani \& Owen, 2004); few animal models of this brain region are available, and there is a need for further research to determine its role in emotion, social behavior, and decision making. By contrast, more is known about the functions of the ventral ACC - in particular, rostral and ventral regions, such as BAs 32 and 25, and ventral parts of BA 24 (Figure 1A).

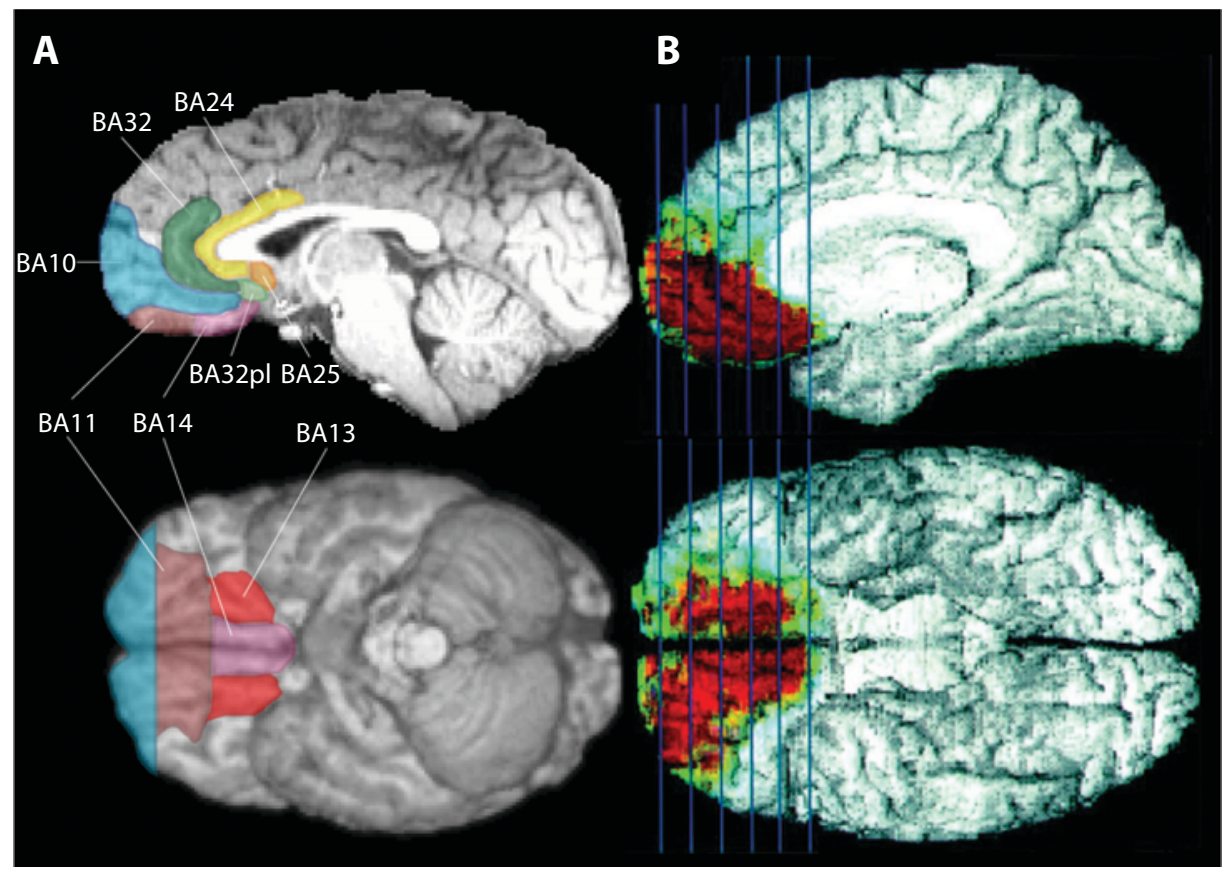

Figure 1. Anatomy and lesions of the ventromedial frontal cortex (VMFC). (A) The anatomical subdivisions of the VMFC from midline (top) and orbital (bottom) views. The different subregions of the OFC, Brodmann areas (BAs) 11, 13, and 14, are marked by the different shaded areas on a normal human brain (see online version for figure in color). The constituent parts of the anterior cingulate cortex (ACC), BAs 24, 32, and 25, are similarly represented by shaded areas on the midline view. The frontal polar cortex (BA 10), the most rostral part of the frontal cortex, is marked on both midline and orbital views of the brain. (B) The extent of lesion overlap in a group of 13 patients with VMFC lesions tested by Bechara, Damasio, and colleagues. These patients with VMFC lesions were impaired on a gambling task that assessed reinforcement-guided decision making. The darker shading (red in online version) in the VMFC indicates the areas associated with the greatest amount of lesion overlap across the 13 subjects. From "Emotion, Decision Making and the Orbitofrontal Cortex," by A. Bechara, H. Damasio, and A. R. Damasio, 2000, Cerebral Cortex, 10, p. 296. Copyright 2000 by Oxford University Press. Adapted with permission. 
The possibility that damage to parts of the ACC may underlie changes in social behavior following VMFC damage has started to receive considerable attention. Human imaging studies suggest a role for the ACC in social interaction and valuation. A number of lesion studies in macaques and rats have also recently provided evidence that this part of the frontal lobe may be specialized for processing social information in all mammals.

Here, we review both the previous work that has highlighted the role of the OFC in emotion and social behavior and the more recent imaging and lesions studies that have focused on the ACC. We will go on to suggest that the OFC may be more specialized for processing emotional information as a consequence of its role in representing sensory information that is related to expectations of primary reinforcers, including both rewards and punishments. OFC-dependent emotions are more directly or immediately related to reinforcement expectations and include responses to fearful objects. Conversely, the ACC, which is interconnected, on the one hand, with autonomic centers and, on the other, with parts of the temporal lobe that are specialized for the processing of biologically and socially meaningful information, such as faces and vocalizations, may play a distinct role in mediating more complex forms of emotional and social behavior. Indeed, the ACC may be especially important for interactions with others and deciding the consequences of interacting with them.

\section{Probing the Function of the VMFC: Human Lesion Studies}

Since the case of Phineas Gage, other patients with similar neurological damage have been reported. One of the most extensively studied patients is known by the initials E.V.R. (A. R. Damasio, Tranel, \& Damasio, 1990; Eslinger \& Damasio, 1985). E.V.R. sustained a bilateral frontal lesion of the VMFC as a result of surgery to remove a tumor. The damage to the VMFC centered on the medial OFC, sometimes referred to as BA 14. The lesion also included ventral parts of the ACC and parts of the lateral OFC. Prior to the operation, E.V.R. was married and employed as an accountant. Postoperatively, although faculties such as intelligence and memory were unaffected, he made a string of ultimately disastrous financial decisions, and his marriage failed as a result of the striking changes in his personality (Eslinger \& Damasio, 1985; Saver \& Damasio, 1991).

The marked changes in personality observed in patient E.V.R. have been linked to subtle changes in the way he processes emotional and social information. In one of the first studies of E.V.R., A. R. Damasio and colleagues found that the patient did not generate normal visceral responses to emotionally charged pictures (A. R. Damasio et al., 1990). Usually, when people are shown such pictures, which might include scenes of mutilation or distressing social situations, they unconsciously show a change in their skin conductance. This change in skin conductance is thought to be an unconscious measure of how emotionally or socially significant the picture is to the person. In patients such as E.V.R., no changes in skin conductance occur when they passively view such pictures. A similar pattern of responses is also seen in sociopaths and psychopaths, which is why E.V.R. and others with similar VMFC damage are sometimes described as having acquired sociopathy (A. R. Damasio et al., 1990; Saver \& Damasio, 1991).

Since these seminal studies of E.V.R., further research has demonstrated that lesions centering on the VMFC cause other changes in the way social and emotional information is processed. In a series of studies, Hornak, Rolls, and colleagues have reported that such patients have deficits in emotion-related learning and subjective emotional experience and are poor at interpreting facial or vocal expressions (Hornak et al., 2003; Hornak, Rolls, \& Wade, 1996; Rolls, Hornak, Wade, \& McGrath, 1994). Related results have been reported by other research groups working with similar patients (Beer, Heerey, Keltner, Scabini, \& Knight, 2003; Heberlein, Padon, Gillihan, Farah, \& Fellows, 2008). It has been argued that VMFC patients' abnormal emotional and social behavior may be the result of an inability to flexibly assign reinforcement value and expectations to stimuli (Rolls, 1999). This hypothesis is based on the finding that the same patients also often perform poorly on visual discrimination reversal tasks, which require the modification of associations between stimuli and reinforcers (Fellows \& Farah, 2003; Hornak et al., 2003).

More subtle deficits in emotion and social behavior have also been reported in patients with VMFC lesions. The work of Beer, Knight, and colleagues has shown that patients with VMFC lesions are less able to generate or recognize emotions with a self-conscious element, such as embarrassment (Beer et al., 2003). When these patients were able to generate self-conscious emotions, they were reported to be maladaptive and reinforcing of inappropriate behavior. In a follow-up study, the researchers showed that the underlying impairment in the VMFC patients might be an inability to monitor their own behavior (Beer, John, Scabini, \& Knight, 2006). This hypothesis might also explain why people with damage to the VMFC have often been reported to have an increased risk of violent and aggressive behavior (Grafman et al., 1996).

Studies of human patients have been essential for the gaining of the initial insight that the VMFC is critical for emotion and social behavior, and in addition, such work has provided clues concerning the mechanisms and processes that are compromised in such patients. However, although there have been some attempts to dissociate the functions of the different subregions of the VMFC in humans (Hornak et al., 2003), this is difficult, since the lesions, often caused by trauma or hemorrhages, do not respect anatomical boundaries. As Figure 1B shows, patients' lesions often include all aspects of the VMFC, with a focus on the medial surface including caudal parts of the frontal polar cortex, ventral ACC, and medial OFC (Bechara et al., 2000). Despite this limitation, anatomical, neurophysiological, and neuropsychological studies in both humans and animals have begun to reveal some of the differences in the contributions made by the OFC and ACC.

\section{Connections of the OFC and ACC}

The OFC and ACC are ideally situated for evaluating the reinforcement significance of events, generating emo- 
tional responses, and guiding social interactions (Carmichael \& Price, 1996; Öngür, An, \& Price, 1998). In macaques, the OFC and ACC are interconnected with brain structures implicated in the processing of reinforcementrelated information, such as the amygdala and ventral striatum (Carmichael \& Price, 1995a; Haber, Kim, Mailly, $\&$ Calzavara, 2006). There are, however, marked differences in the patterns of other connections (Carmichael \& Price, 1995a; Van Hoesen, Morecraft, \& Vogt, 1993). The OFC receives information from nearly all the different sensory modalities. Visual information reaches the OFC from the inferior temporal and perirhinal cortex, and olfactory, taste, and somatic sensory information is received by distinct parts of the OFC (Carmichael \& Price, 1995a, 1995b; Kondo, Saleem, \& Price, 2005; Saleem, Kondo, \& Price, 2008). Sensory projections to the ACC, by contrast, are sparse or even absent (Carmichael \& Price, 1995b). Diffusion weighted imaging tractography studies suggest that a similar disparity in sensory connections is also apparent in the human brain (Croxson et al., 2005).

Instead, the ACC in macaques is densely interconnected with subcortical structures that control autonomic and visceral responses, such as the hypothalamus, periaqueductal gray matter, and distinct parts of the amygdala (Öngür, An, \& Price, 1998). Again, tractography studies suggest a similar pattern of connections in the human brain (Johansen-Berg et al., 2008). One of the few sensory projections to reach the ACC in macaques comes from auditory areas in the temporal lobe. Both auditory association cortex and polymodal areas in the ventrolateral and superior temporal cortex, respectively, project to distinct parts of the ACC (Barbas, Ghashghaei, Dombrowski, \& Rempel-Clower, 1999; Galaburda \& Pandya, 1983; Kondo, Saleem, \& Price, 2003; Saleem et al., 2008; Seltzer \& Pandya, 1978; Van Hoesen et al., 1993). Anatomical and physiological studies have shown that these parts of the temporal lobe not only process complex auditory information, but also are intimately involved in integrating dynamic, highly processed visual and auditory information, such as species-specific vocalizations and facial expressions (Bruce, Desimone, \& Gross, 1981; Ghazanfar, Maier, Hoffman, \& Logothetis, 2005; Poremba et al., 2004). Although we often tend to think of higher order auditory processing in the service of language, there is good evidence that the vocalizations of macaques serve as indexical cues as to the caller's size, identity, and social status (Ghazanfar et al., 2007), and similar mechanisms are present in the human brain (Belin, 2006). By contrast, the OFC receives relatively few connections from these auditory association areas, and those parts of the OFC that do are densely interconnected with parts of the ACC (Saleem et al., 2008).

On the basis of this striking difference in connectivity, Price and colleagues have suggested that two distinct functional networks exist in the orbital and medial prefrontal cortex (Carmichael \& Price, 1996). They propose that one network, most closely associated with the OFC, is principally specialized for identifying and evaluating primary rewards and punishers by virtue of its connections to sensory areas (Price, 2005; Saleem et al., 2008). The other network is often described as centered on the medial orbitofrontal cortex, but it includes parts of the ACC, including BAs 32, 24, and 25. This network, it is hypothesized, is specialized for modulating more complex emotional behavior, which might include social interactions, on the basis of its connections to autonomic areas.

\section{OFC and Decision Making}

It is now generally accepted that the OFC is specialized for high-level aspects of reinforcement-guided behavior and decision making (Murray, O'Doherty, \& Schoenbaum, 2007; Roberts, 2006; Schoenbaum \& Roesch, 2005; Wallis, 2007). Numerous studies have shown that this part of the frontal lobe is involved in stimulus-reward associations, representing the expected value of different options and abstract rules. All of these processes are essential for optimal decision making but also, potentially, for guiding normal emotional responses to sensory stimuli.

Lesion studies in macaques were some of the first to suggest a role for the OFC in stimulus-reward associations (Iversen \& Mishkin, 1970; McEnaney \& Butter, 1969). Specifically, destruction of the OFC does not disrupt the formation of stimulus-reward associations but affects the ability of macaques to flexibly reassign value to previously unrewarded stimuli (Izquierdo, Suda, \& Murray, 2004). More recently, reinforcement devaluation studies have further emphasized the role of the OFC in altering reinforcement or outcome expectancies associated with stimuli (Baxter, Parker, Lindner, Izquierdo, \& Murray, 2000; Izquierdo et al., 2004). Reports from human lesion and neuroimaging work have confirmed and extended these findings. Patients with damage to the frontal lobe that includes the OFC are less able to flexibly alter stimulus-reward associations (Fellows \& Farah, 2003; Hornak et al., 2004). Haemodynamic responses in the OFC have been reported to correlate with the expected value associated with different gustatory, visual, olfactory, and somatosensory stimuli (for a review, see O'Doherty, 2007).

Complementing results from ablation and neuroimaging studies, recordings from macaque OFC neurons show that cells in this area encode the value of expected reward or punishment associated with different visual stimuli (Roesch \& Olson, 2004, 2005; Schultz, Tremblay, \& Hollerman, 2000; Wallis \& Miller, 2003). Building on these findings, a recent study by Padoa-Schioppa and Assad (2006) has revealed that when a macaque chooses between two options, neurons in the OFC represent the economic value of the potential rewards associated with each. In the study, macaques chose between two stimuli that were associated with different amounts of two types of juice, one for which they had a preference and one for which they did not. By systematically varying the amount of each juice associated with each option, the authors were able to determine the point at which the animals were equally likely to choose either option, known as the indifference point. The indifference point reflected the macaques' relative valuation of one of the types of juice, in comparison with the other. Padoa-Schioppa and Assad showed that the activity of cells in the OFC very closely matched the 
macaques' relative valuation of the potential options that were available. OFC neurons also encoded the value of the option that the macaques ultimately selected. Choicerelated activity in the OFC suggests that these neurons encoded the subjective utility or economic value of the reward to the animal.

Neuroimaging studies in humans have similarly suggested a role for the OFC in economic choice (Arana et al., 2003; Montague \& Berns, 2002; Plassmann, O’Doherty, \& Rangel, 2007). Changes in the BOLD response in the OFC have been reported to vary as a function of the value and magnitude of abstract rewards (such as money) and punishment (loss of money) (Knutson, Fong, Adams, Varner, \& Hommer, 2001; O'Doherty, Kringelbach, Rolls, Hornak, \& Andrews, 2001). Furthermore, abstract reward and punishment were associated with activations in distinct parts of the OFC. Whereas reward or receipt of money was associated with increased activity in the medial OFC, punishment or loss of money was associated with increased activity in the lateral OFC (O'Doherty et al., 2001). A similar medial-lateral dissociation has also been reported during tasks in which participants had to choose between different options on the basis of the costs and benefits associated with each (McClure, Ericson, Laibson, Loewenstein, \& Cohen, 2007; McClure, Laibson, Loewenstein, \& Cohen, 2004; Tanaka et al., 2004). Activations in the more medial OFC were reported when the subjects chose options associated with low cost and immediate reward, whereas the lateral OFC was more active when the subjects chose options associated with higher costs and delayed reward (McClure et al., 2007; McClure et al., 2004; Tanaka et al., 2004). Although these reports provide evidence that there may be a medial-lateral functional dissociation within the OFC, an important avenue for future research will be to determine whether other processes are carried out by discrete parts of the OFC.

\section{OFC and Emotion}

The OFC's role in emotion is as well established as its contribution to reward-guided behavior and decision making. A central role for the OFC in regulating emotion is based on the finding that marked changes in emotion follow damage to the VMFC in humans. However, as the previous sections have suggested, studies in humans cannot rule out the possibility that some of the patients' strange emotional and social behavior is the result of damage to other parts of the VMFC, and not just to the OFC alone. Instead, some of the best evidence for a role of the OFC in emotion has come from studies of animals with circumscribed lesions.

The majority of investigations of the role of the OFC in emotion have relied on the fact that macaques have an innate natural fear of snakes and perceive unfamiliar humans as threatening (Butter, Snyder, \& McDonald, 1970; Mineka, Keir, \& Price, 1980). Macaques' fear of snakes is most commonly assessed using variants of a task developed by Mineka and colleagues (Mineka et al., 1980). In the task, the macaques' fear of snakes is assessed by placing a piece of food valuable to the animals near a toy snake. The macaques are then given the opportunity to retrieve the piece of food, and their latency to do so indexes how fearful they are of the snake. Normal control macaques show an innate fear of snakes, retrieving the piece of food only after relatively long latencies, if at all. Macaques with damage to the OFC, by contrast, are less fearful of snakes, reliably retrieving the piece of food (Izquierdo, Suda, \& Murray, 2005). The same macaques with OFC damage that have short latencies to retrieve the food are also more aggressive to unfamiliar humans, in comparison with unoperated control animals (Izquierdo et al., 2005). More ethological tests looking at the effects of OFC lesions on social interaction between macaques have similarly shown that destruction of this frontal area leads to a more aggressive pattern of behavior (Machado \& Bachevalier, 2006). These same animals are, like patients with VMFC lesions, impaired at visual discrimination reversal learning tasks (Izquierdo et al., 2004; Machado \& Bachevalier, 2007).

The important similarity between the impairments of OFC-lesioned animals and human patients with VMFC lesions underscores the important contribution of the $\mathrm{OFC}$ to the emotional disturbances of VMFC patients. In addition, the close association between emotional impairment and impairment in the ability to flexibly learn stimulusreinforcement associations after OFC lesions has led to the argument that the latter inability may underlie the former (Rolls, 1999). According to this view, if an animal or person with an OFC lesion is unable to predict the reinforcement consequence of a stimulus, the normal emotional response to the stimulus will be lacking too.

Even studies of rats with OFC damage have reported a similar pattern of emotional behavior. Following either aspiration or electrolytic lesions of the $\mathrm{OFC}$, rats are more aggressive in tests of social interaction (de Bruin,Van Oyen, \& Van de Poll, 1983; Kolb, 1974). Recently, a study suggested that the increased aggressive behavior in rats following OFC lesions may be the result of altered reward processing (Rudebeck et al., 2007). Consistent with previous reports (de Bruin et al., 1983; Kolb, 1974), excitotoxic lesions of the OFC produced a mild but significant increase in the aggressive behavior of the rats (Rudebeck et al., 2007). The same rats were also tested on a series of anxiety and decision-making tests. Damage to the OFC was associated with decreased anxiety-related behavior, but only in a test involving food rewards (Rudebeck et al., 2007). On a delaybased decision-making task, in which they had to choose between two options on the basis of the costs and benefits associated with each, rats with OFC lesions also showed impairments in reward encoding (Rudebeck, Walton, Smyth, Bannerman, \& Rushworth, 2006). Taken together, these findings are of interest because, first, they provide evidence for potential functional homologies across species and, second, they suggest that increased risk of aggressive and violent behavior in human patients following VMFC lesions may, to some extent, be contingent on damage to the OFC alone.

\section{Human ACC and Social Interaction}

Damage to the ACC in patients with VMFC lesions often destroys parts of BAs 32 and 25 and, probably, some portions of ventral area 24a (Figure 1B). As after an OFC lesion, changes in emotion and social behavior have also 
been reported following damage to, or dysfunction within, the ACC in humans (Cummings, 1993; Rosen et al., 2005). Destruction of the ACC is associated with apathy and, in some extreme cases, akinetic mutism, although it should be noted that akinetic mutism is also associated with damage to other parts of the brain (Cummings, 1993; Grafman et al., 1996; Laplane, Degos, Baulac, \& Gray, 1981). Although not emphasized at the time, the findings from one of the previously mentioned studies in humans by Hornak and colleagues (Hornak et al., 2003) suggest that the social changes seen after VMFC lesion may, to some extent, be contingent on damage to the ACC. The authors reported that in comparison with even bilateral OFC lesions, those patients with lesions encroaching into the ACC - in particular, BA 32-were associated with the most extreme changes in recognizing and evaluating social cues (Hornak et al., 2003).

Neuroimaging studies have complemented and extended these findings. Although the majority of lesion studies have focused on simple measures of emotional responsiveness or on questionnaires for social responsiveness (Hornak et al., 2003; Hornak et al., 1996), imaging studies have sometimes used more complex paradigms that examine the interactions between individuals. Using interpersonal paradigms, it has been possible to establish which areas of the brain are important when subjects interact, or think that they are interacting, with other people or responsive agents (Amodio \& Frith, 2006; C. D. Frith \& U. Frith, 1999). For example, in one study, subjects played rock, paper, scissors, a game in which there are just three responses to choose but the best response depends on what the opponent also chooses (Gallagher, Jack, Roepstorff, \& Frith, 2002). Subjects therefore attempt both to ensure that their own intentions are not revealed to their opponent and to second-guess the choice that their opponent is likely to make. Parts of BA 32 were active when the subjects thought that they were playing against another person, but less activity was recorded when the subjects thought that they were playing against a computer program, even though a similar response generation algorithm was used in both conditions (Gallagher et al., 2002). A number of studies have described activations in the ACC during social interactions or tasks that require subjects to evaluate social information (Amodio \& Frith, 2006; Somerville, Heatherton, \& Kelley, 2006). Activations in the ACC and the adjacent dorsomedial frontal cortex have been reported when subjects have to encode and retrieve social information, as well as when they receive social feedback from other people (Mitchell, Macrae, \& Banaji, 2004; Ochsner et al., 2005; Somerville et al., 2006). In one study, subjects were shown pictures of several individuals and were required either to form an impression of the people in the images or to remember the order of the images. Medial frontal and ACC activity was greater in the former case, and it was predictive of subsequent recall of social information in a memory test (Mitchell et al., 2004). Intriguingly, the location of activity in medial frontal areas during social judgments is related to the degree to which the person being judged is perceived as being similar or dissimilar to oneself (Mitchell, Macrae, \& Banaji, 2006).
Imaging studies have also shown that the ACC is important when subjects perform tasks that require cooperation with another person, such as the prisoners' dilemma game (Rilling et al., 2002) and the trust game (King-Casas et al., 2005). In both of these paradigms, the best choice for the subject depends on the choices that the other player makes. There is, therefore, similarly an implicit need to form an impression of the other player and the choices that he or she is likely to make. Activations in the ACC during the trust game are agent specific, with different areas being activated depending on whether the subject him- or herself makes a move or the other player makes a move that is then observed (Tomlin et al., 2006). Activations in the ACC are prominent when subjects think that another player or agent makes a move or decision. Furthermore, as in the experiments performed by Gallagher and Frith and colleagues, when subjects interact with partners they know to be just computers, these activations are not seen, suggesting that they reflect the interpersonal nature of the task (Gallagher et al., 2002; Rilling, Sanfey, Aronson, Nystrom, \& Cohen, 2004; Tomlin et al., 2006).

\section{The ACC and Psychological Disorders}

A role for the different parts of the ACC in regulating social behavior has also been suggested from imaging studies of clinical populations. Frontotemporal dementia (FTD) is a disorder associated with degeneration of the frontal cortex (Neary, Snowden, Northen, \& Goulding, 1988). Patients presenting with FTD often fall into one of two categories: those with impairments in executive function and those with severe alterations in social behavior (Neary, Snowden, \& Mann, 2000). Voxel-based morphometry studies of patients with FTD suggest that different social changes exhibited by these people, apathy and disinhibition, are contingent on tissue loss in BA 32 and BA 25, respectively (Rosen et al., 2005). Degeneration of the cortex in the region of BA 32 was associated with apathy. By contrast, behavioral disinhibition was correlated with the degree of tissue loss in BA 25.

Structural and functional abnormalities in BA 25 have also been reported in patients with major depression. In an elegant series of studies, Drevets and colleagues first showed that patients with major depression had reduced metabolic activity in the subgenual ACC (Drevets et al., 1997). Voxel-based morphometry and postmortem analysis revealed that the volume of the subgenual ACC in the brains of these patients was reduced and that the reduction was due to decreased levels of glial cells within rostral and ventral parts of BA 24 (Öngür, Drevets, \& Price, 1998). Intriguingly, this work has led to the development of a treatment for patients with major depression, which uses stimulating electrodes targeting the white matter near BA 24 to modulate activity in this area (Mayberg et al., 2005).

On the basis of the preceding discussion, it is tempting to speculate that damage or dysfunction within the ACC may underlie all disorders in which normal patterns of social interaction are affected. One such disorder that affects social behavior is autism. People diagnosed with autism often have normal and even, sometimes, better than normal cognitive abilities but show severe deficits in social inter- 
action (American Psychiatric Association, 2000; U. Frith, 2001). Imaging studies in children, adolescents, and adults have reported that these deficits in social behavior may be associated with abnormalities in the ACC in autistic individuals (Castelli, Frith, Happé, \& Frith, 2002; Chiu et al., 2008; Ohnishi et al., 2000). Using SPECT imaging techniques, Ohnishi and colleagues first showed that, as compared with control subjects, children with autism showed abnormal regional cerebral blood flow in the prefrontal and temporal cortices (Ohnishi et al., 2000). Second, when these changes were correlated with the severity of each autistic child's symptoms, deficits in social interaction and communication were closely associated with decreased blood flow in the area of the ACC - specifically, in the region of BA 32. Data from imaging studies have similarly shown a relationship between functional abnormalities in the ACCs of autistic individuals and the same individuals' symptom severities and behavioral deficits (Castelli et al., 2002; Kennedy, Redcay, \& Courchesne, 2006).

\section{A Role for the ACC in Social Behavior in Animals}

Although it is challenging to objectively study social interaction in animals, as opposed to emotional responsiveness in terms of fearfulness and aggression, a number of experimental paradigms have been valuable in identifying the critical neural circuits. Tests in which macaques are presented with either snakes or unfamiliar humans, as well as fear-conditioning paradigms in rats, have been influential (Lacroix, Spinelli, Heidbreder, \& Feldon, 2000; Murray \& Izquierdo, 2007; Quirk, Garcia, \& GonzálezLima, 2006). Tests of conditioned fear and subsequent extinction of this fear have been especially compelling, since they have allowed direct comparisons to be made between human imaging and rat lesion studies (Quirk \& Beer, 2006). However, although studying fear and aggression in animals has elucidated how information of an emotional nature is processed in the VMFC, it provides less insight into the role of this area in mediating more complex forms of emotion and social behavior, such as interactions between individuals. Instead, it may be useful to consider alternative methods that take a more ethological approach to studying social interaction and evaluation.

Taking such an approach, a number of groups have been able to develop experimental paradigms that objectively determine how animals evaluate social information and the neural structures involved in these processes (Deaner, Khera, \& Platt, 2005; Gothard, Battaglia, Erickson, Spitler, \& Amaral, 2007; Hoffman, Gothard, Schmid, \& Logothetis, 2007; Rudebeck, Buckley, Walton, \& Rushworth, 2006). In one of these studies, Deaner, Platt, and colleagues assessed how much male macaques valued different social stimuli by measuring their responses to images of other male and female macaques (Deaner et al., 2005). The researchers determined the relative value thirsty macaques assigned to the different social images by pitting the opportunity to see a potentially interesting image and an amount of juice reward against receiving just juice alone (Figure 2). By systematically varying the amount of juice associated with not seeing a social image, Deaner and colleagues were able to determine the relative value of a number of dif- ferent images of conspecifics. The male macaques in the study valued the opportunity, or gave up the juice reward, to see images of dominant male macaques and the perinea of female macaques. By contrast, they did not value the opportunity to view pictures of subordinate macaques and, in some cases, would choose to view these pictures only if they were paid extra juice reward.

Building on these intriguing results, Rudebeck and colleagues conducted a similar set of experiments that measured the social or emotional value that macaques assigned to videos of other macaques (Rudebeck, Buckley, et al., 2006). The value of the different video stimuli was assessed by measuring how long it took the macaques to retrieve a food reward placed near the video monitor. The macaques' latencies to retrieve the food rewards provided an index of the value of obtaining further information about the stimulus before reaching; the latency reflects the monkeys' relative valuation of the stimulus in contrast to the incentive value of the food. Among normal macaques, there was broad agreement as to which stimuli were more interesting or valuable (Figure $3 \mathrm{~A}$ ). Consistent with the results in Deaner et al. (2005), macaques were slower to retrieve food rewards when videos of either socially dominant macaques or female perinea were presented. As in the previous studies, longer retrieval latencies were also seen when moving toy snakes were presented. In addition to control animals, however, Rudebeck and colleagues assessed the performance of two groups of monkeys with different frontal lesions. One group had OFC lesions, whereas the other had lesions restricted to the ACC gyrus that included BA 32 and anterior parts of BA 24. As had been seen in other studies, macaques with OFC lesions exhibited a reduction in emotional responsiveness to the toy snakes (Izquierdo et al., 2005). The greatest and most consistent reductions in valuation assigned to social information, however, followed ACC gyrus lesions. The reaching latencies of macaques with ACC gyrus lesions were not modulated by the identities of the conspecific individuals they were shown (Figure 3A). The same ACC gyrus-lesioned macaques also performed the visual discrimination reversal learning task used to assess stimulus reinforcement association without impairment. Therefore, unlike after OFC lesions, changes in social valuation that follow ACC gyrus lesions cannot be linked to an inability to flexibly alter stimulus reinforcement associations (Rudebeck, Buckley, et al., 2006).

It has previously been observed that macaques spend less time in proximity with one another after larger ACC lesions that include the ACC gyrus (Hadland, Rushworth, Gaffan, \& Passingham, 2003). The results obtained by Rudebeck and colleagues suggest that this may be a consequence of a lowered valuation of information pertaining to other individuals. Other aspects of social behavior, facial gestures such as lip smacking and vocalizations such as contact calls, made when animals lack sight of one another, are also reduced after lesions that include the ACC gyrus (Hadland et al., 2003; Rudebeck, Buckley, et al., 2006).

Another important question is whether a part of the ACC in all mammals, and not just primates, is essential for processing social information. Areas of the human 


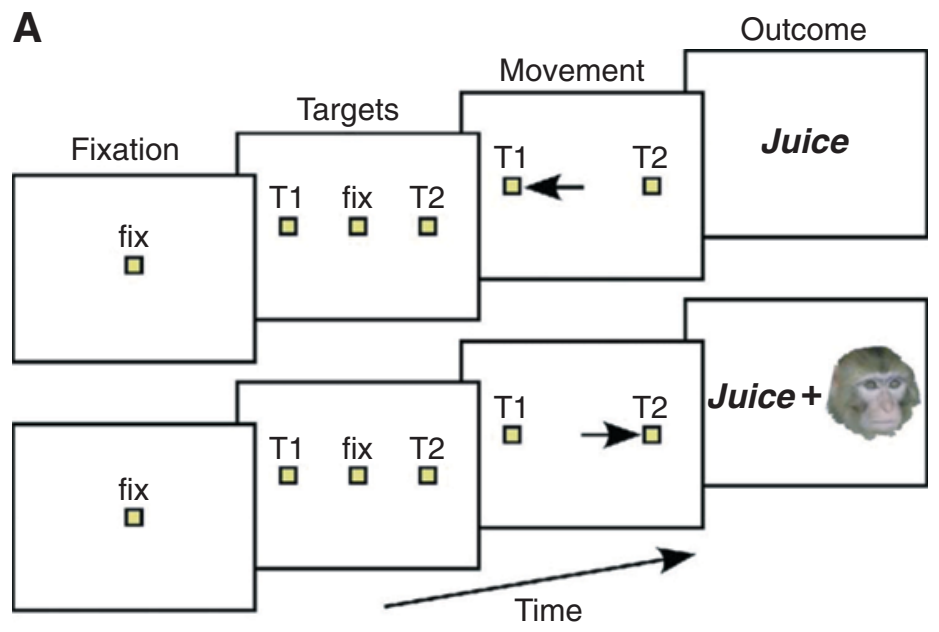

B

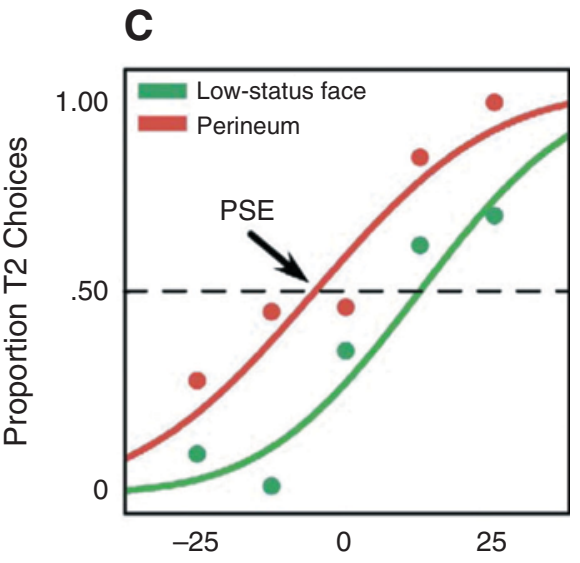

Relative Juice Payoff for T2 (\% Juice)

Figure 2. Determining the relative value macaques assign to different types of social image. (A) Macaques were trained to fixate a central spot. Once they did so, two potential targets appeared to the left and right, which were associated either with juice alone or with receiving juice as well as the opportunity to view an image of another macaque. The central spot was then extinguished, which instructed the macaque to make a saccade to one of the two targets. (B) Examples of two of the types of stimuli presented, an image of a female macaque perineum and a macaque with a high-dominance status. (C) By calculating the point of subjective equivalence (PSE), the amount of juice needed for macaques to select an image on $50 \%$ of the trials, for each of the different image types, Deaner and colleagues were able to determine the relative value each macaque assigned to that image type. In comparison with images of macaques of lowdominance status (rightmost line, green in online version), thirsty male macaques accepted less juice or assigned higher value to the opportunity to view images of female macaque perinea (leftmost line, red in online version). Male macaques also valued the opportunity to view images of high-status macaques more than those of low-status macaques (data not shown). From "Monkeys Pay Per View: Adaptive Valuation of Social Images by Rhesus Macaques,” by R. O. Deaner, A. V. Khera, and M. L. Platt, 2005, Current Biology, 15, p. 544. Copyright 2005 by Elsevier. Reprinted with permission.

and macaque ACC have homologues in rodents (Vogt \& Peters, 1981). It is possible that social interaction is mediated by these comparable areas in all these species. Indeed, a recent study in rats suggests that this may well be the case. In this study, unfamiliar pairs of rats drawn from groups with either ACC or sham lesions were allowed to interact with one another, and their behavior was recorded (Rudebeck et al., 2007). When presented with this situation, control rats usually spend a large amount of time socially interacting, exploring, and sniffing the other rat, whereas aggressive behaviors, such as biting and upright boxing, account for only a small amount of the time spent (Bannerman et al., 2002; McHugh, Deacon, Rawlins, \& Bannerman, 2004; Shah \& Treit, 2003). Fol- 
A

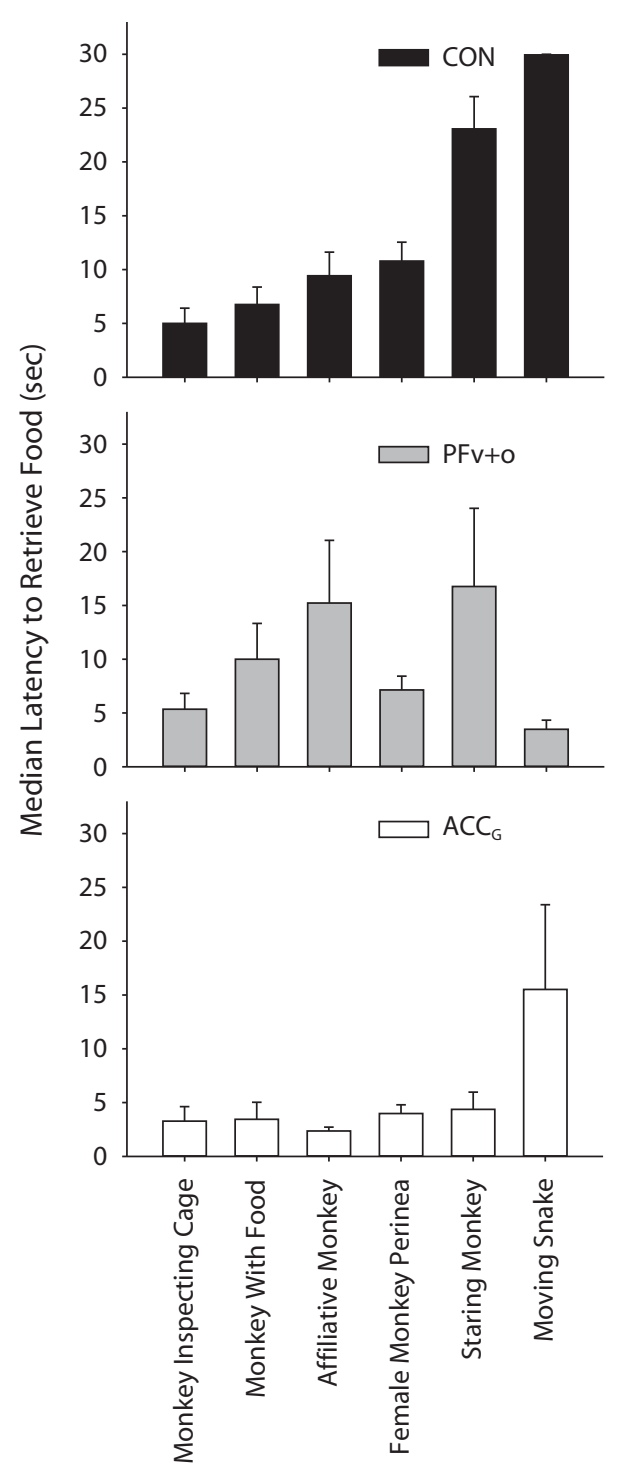

B

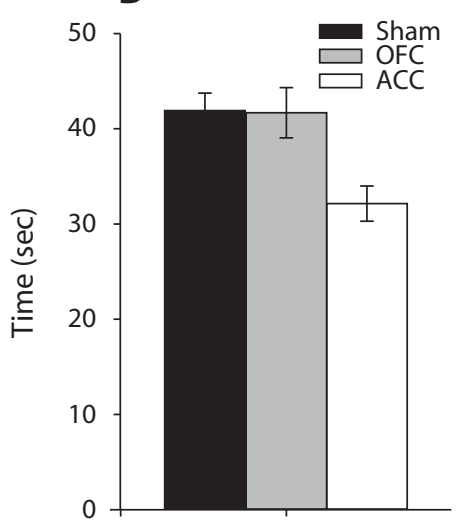

Social Behavior

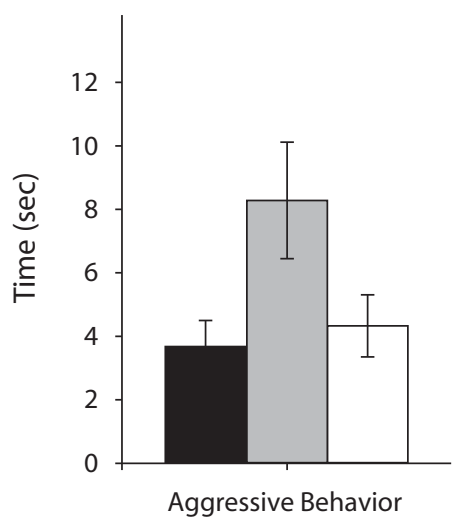

Figure 3. The effects of orbitofrontal cortex (OFC) and anterior cingulate cortex (ACC) lesions in macaques and rats on emotion and social behavior. (A) The median latency of macaques to retrieve a food reward in the presence of either social stimuli or a mildly fearinducing stimulus. Social stimuli were videos of other macaques, and the mild fear stimulus was a moving toy snake. The latencies of unoperated controls (con; top) and macaques with damage to either the ventral prefrontal/OFC (PFv+o; middle) or the $\mathrm{ACC}$ gyrus $\left(\mathrm{ACC}_{\mathrm{G}}\right.$; bottom) are shown. Although macaques with lesions that encroached into the $\mathrm{OFC}$ showed normal responses to social stimuli, they consistently retrieved food placed near moving snakes. Animals with $\mathrm{ACC}_{\mathrm{G}}$ lesions, by contrast, showed the opposite pattern of behavior, reliably retrieving food when social stimuli were presented (Rudebeck, Buckley, Walton, \& Rushworth, 2006). Error bars represent standard errors of the means. (B) The effect of excitotoxic OFC or ACC lesions on social behavior in the rat. The total amount of time animals spent engaged in either aggressive $(M \pm S E M)$ or social behaviors $(M \pm S E M)$ during the 300-sec social interaction test.

lowing ACC lesions, rats exhibited a different pattern of behavior, spending comparatively less time socially interacting with one another than did sham lesion animals (Figure 3B). Similar to the findings in macaques, tests of anxiety confirmed that the ACC-lesion-associated de- crease in social interaction was not simply a concomitant of changes in other aspects of emotional responsiveness (Rudebeck, Buckley, et al., 2006).

A role for the rodent ACC in social behavior has also been highlighted by a recent series of genetic knockout 
studies in mice (Cholfin \& Rubenstein, 2007; ScearceLevie et al., 2008). In an elegant series of studies, Cholfin and colleagues have shown that fibroblast growth factor 17 (Fgf17) specifically controls the development and patterning of the dorsal frontal cortex in mice (Cholfin \& Rubenstein, 2007). Animals lacking the gene that encodes for Fgf17 have a smaller and less developed dorsal frontal cortex, including the ACC. Behaviorally, these same mice show a range of impairments in social interaction, including decreased vocalizations in social situations and altered patterns of social interaction (Scearce-Levie et al., 2008). In combination with the results from human studies, the findings from both macaques and rodents suggest the possibility that an area within the ACC may be specialized for processing social information in all mammals.

\section{Conclusions and Future Directions}

Gaining insights into how parts of the frontal lobe contribute to emotion and social behavior is critically important for understanding not only normal brain function, but also dysfunction. Converging lines of evidence now suggest that anatomically distinct parts of the VMFC may make dissociable contributions to emotion and social behavior. Although there is a clear and undisputable role for the $\mathrm{OFC}$ in processing emotional information, the ACCin particular, BA 32 in primates, including humans - may be specialized for evaluating social information.

To assume, however, that these parts of the frontal cortex alone are sufficient for regulating our emotions and social behavior would be to overlook a wealth of research. Other parts of the cerebral cortex and subcortical structures, especially the amygdala and superior temporal sulcus, are also crucial for emotional regulation and normal patterns of social behavior (Adolphs, 2001; Adolphs, Tranel, Damasio, \& Damasio, 1994; Apperly, Samson, Chiavarino, \& Humphreys, 2004; Emery et al., 2001; Izquierdo et al., 2005; Machado \& Bachevalier, 2006; Meunier, Bachevalier, Murray, Málková, \& Mishkin, 1999; Samson, Apperly, Chiavarino, \& Humphreys, 2004). Both the OFC and the ACC are differentially interconnected with the amygdala and different parts of the temporal lobe (Carmichael \& Price, 1995a; Van Hoesen et al., 1993). Investigating how these structures influence each other and interact to produce normal patterns of emotion and social behavior will be important. Furthermore, exploring how processing within and interaction between these brain regions is altered in psychological disorders will be an exciting and important avenue for future research.

\section{AUTHOR NOTE}

We thank the Medical Research Council (P.H.R. and M.F.S.R.) and the Wellcome Trust (D.M.B.) for support, and D. Gorrin, B. B. Herman, and three anonymous reviewers for useful comments on the manuscript. Correspondence concerning this article should be addressed to P. H. Rudebeck, Laboratory of Neuropsychology, Building 49, Suite 1B80, 49 Convent Drive, Bethesda, MD 20892-4415 (e-mail: rudebeckp@mail.nih.gov).

\section{REFERENCES}

Adolphs, R. (2001). The neurobiology of social cognition. Current Opinion in Neurobiology, 11, 231-239.
Adolphs, R., Tranel, D., Damasio, H., \& Damasio, A. [R.] (1994). Impaired recognition of emotion in facial expressions following bilateral damage to the human amygdala. Nature, 372, 669-672.

American Psychiatric Association. (2000). Diagnostic and statistical manual of mental disorders: DSM-IV-TR (4th ed., text revision). Washington DC: American Psychiatric Association.

Amodio, D. M., \& Frith, C. D. (2006). Meeting of minds: The medial frontal cortex and social cognition. Nature Reviews Neuroscience, 7 , 268-277.

Apperly, I. A., Samson, D., Chiavarino, C., \& Humphreys, G. W. (2004). Frontal and temporo-parietal lobe contributions to theory of mind: Neuropsychological evidence from a false-belief task with reduced language and executive demands. Journal of Cognitive Neuroscience, 16, 1773-1784.

Arana, F. S., Parkinson, J. A., Hinton, E., Holland, A. J., Owen, A. M., \& Roberts, A. C. (2003). Dissociable contributions of the human amygdala and orbitofrontal cortex to incentive motivation and goal selection. Journal of Neuroscience, 23, 9632-9638.

Bannerman, D. M., Deacon, R. M. J., Offen, S., Friswell, J., Grubb, M., \& Rawlins, J. N. P. (2002). Double dissociation of function within the hippocampus: Spatial memory and hyponeophagia. Behavioral Neuroscience, 116, 884-901.

Barbas, H., Ghashghaei, H., Dombrowski, S. M., \& RempelClower, N. L. (1999). Medial prefrontal cortices are unified by common connections with superior temporal cortices and distinguished by input from memory-related areas in the rhesus monkey. Journal of Comparative Neurology, 410, 343-367.

Baxter, M. G., Parker, A., Lindner, C. C. C., Izquierdo, A. D., \& Murray, E. A. (2000). Control of response selection by reinforcer value requires interaction of amygdala and orbital prefrontal cortex. Journal of Neuroscience, 20, 4311-4319.

Bechara, A., Damasio, A. R., Damasio, H., \& Anderson, S. W. (1994). Insensitivity to future consequences following damage to human prefrontal cortex. Cognition, 50, 7-15.

Bechara, A., Damasio, H., \& Damasio, A. R. (2000). Emotion, decision making and the orbitofrontal cortex. Cerebral Cortex, 10, 295-307.

Bechara, A., Damasio, H., Tranel, D., \& Damasio, A. R. (1997). Deciding advantageously before knowing the advantageous strategy. Science, 275, 1293-1295.

Beer, J. S., Heerey, E. A., Keltner, D., Scabini, D., \& Knight, R. T. (2003). The regulatory function of self-conscious emotion: Insights from patients with orbitofrontal damage. Journal of Personality \& Social Psychology, 85, 594-604.

BeER, J. S., John, O. P., SCABINI, D., \& KNIGHT, R. T. (2006). Orbitofrontal cortex and social behavior: Integrating self-monitoring and emotioncognition interactions. Journal of Cognitive Neuroscience, 18, 871-879.

BELIN, P. (2006). Voice processing in human and non-human primates. Philosophical Transactions of the Royal Society B, 361, 2091-2107.

Berg, J., Dickhaut, J., \& McCabe, K. (1995). Trust, reciprocity, and social history. Games \& Economic Behavior, 10, 122-142.

Bruce, C., Desimone, R., \& Gross, C. G. (1981). Visual properties of neurons in a polysensory area in superior temporal sulcus of the macaque. Journal of Neurophysiology, 46, 369-384.

Butter, C. M., SNyder, D. R., \& MCDonald, J. A. (1970). Effects of orbital frontal lesions on aversive and aggressive behaviors in rhesus monkeys. Journal of Comparative \& Physiological Psychology, 72, 132-144.

Camille, N., Coricelli, G., Sallet, J., Pradat-Diehl, P., Duhamel, J.-R., \& Sirigu, A. (2004). The involvement of the orbitofrontal cortex in the experience of regret. Science, 304, 1167-1170.

Carmichael, S. T., \& Price, J. L. (1995a). Limbic connections of the orbital and medial prefrontal cortex in macaque monkeys. Journal of Comparative Neurology, 363, 615-641.

Carmichael, S. T., \& Price, J. L. (1995b). Sensory and premotor connections of the orbital and medial prefrontal cortex of macaque monkeys. Journal of Comparative Neurology, 363, 642-664.

Carmichael, S. T., \& Price, J. L. (1996). Connectional networks within the orbital and medial prefrontal cortex of macaque monkeys. Journal of Comparative Neurology, 371, 179-207.

Castelli, F., Frith, C. [D.], Happé, F., \& Frith, U. (2002). Autism, Asperger syndrome and brain mechanisms for the attribution of mental states to animated shapes. Brain, 125, 1839-1849. 
Chiu, P. H., Kayali, M. A., Kishida, K. T., Tomlin, D., Klinger, L. G., Klinger, M. R., \& Montague, P. R. (2008). Self responses along cingulate cortex reveal quantitative neural phenotype for highfunctioning autism. Neuron, 57, 463-473.

Cholfin, J. A., \& Rubenstein, J. L. (2007). Patterning of frontal cortex subdivisions by Fgf17. Proceedings of the National Academy of Sciences, 104, 7652-7657.

Croxson, P. L., Johansen-Berg, H., Behrens, T. E. J., Robson, M. D., PINSK, M. A., Gross, C. G., ET AL. (2005). Quantitative investigation of connections of the prefrontal cortex in the human and macaque using probabilistic diffusion tractography. Journal of Neuroscience, 25, 8854-8866.

Cummings, J. L. (1993). Frontal-subcortical circuits and human behavior. Archives of Neurology, 50, 873-880.

Damasio, A. R., Tranel, D., \& Damasio, H. (1990). Individuals with sociopathic behavior caused by frontal damage fail to respond autonomically to social stimuli. Behavioural Brain Research, 41, 81-94.

Damasio, H., Grabowski, T., Frank, R., Galaburda, A. M., \& Damasio, A. R. (1994). The return of Phineas Gage: Clues about the brain from the skull of a famous patient. Science, 264, 1102-1105.

Deaner, R. O., Khera, A. V., \& Platt, M. L. (2005). Monkeys pay per view: Adaptive valuation of social images by rhesus macaques. Current Biology, 15, 543-548.

de Bruin, J. P., van Oyen, H. G., \& VAn de Poll, N. (1983). Behavioural changes following lesions of the orbital prefrontal cortex in male rats. Behavioural Brain Research, 10, 209-232.

Drevets, W. C., Price, J. L., Simpson, J. R., JR., Todd, R. D., Reich, T., VAnNier, M., \& RaIChle, M. E. (1997). Subgenual prefrontal cortex abnormalities in mood disorders. Nature, 386, 824-827.

Emery, N. J., Capitanio, J. P., Mason, W. A., Machado, C. J., MenDOZA, S. P., \& Amaral, D. G. (2001). The effects of bilateral lesions of the amygdala on dyadic social interactions in rhesus monkeys (Macaca mulatta). Behavioral Neuroscience, 115, 515-544.

Eslinger, P. J., \& Damasio, A. R. (1985). Severe disturbance of higher cognition after bilateral frontal lobe ablation: Patient EVR. Neurology, 35, 1731-1741.

Fellows, L. K., \& FARAH, M. J. (2003). Ventromedial frontal cortex mediates affective shifting in humans: Evidence from a reversal learning paradigm. Brain, 126, 1830-1837.

Fellows, L. K., \& FARAH, M. J. (2007). The role of ventromedial prefrontal cortex in decision making: Judgment under uncertainty or judgment per se? Cerebral Cortex, 17, 2669-2674.

Frith, C. D., \& Frith, U. (1999). Interacting minds-a biological basis. Science, 286, 1692-1695.

Frith, U. (2001). Mind blindness and the brain in autism. Neuron, 32, 969-979.

Galaburda, A. M., \& Pandya, D. N. (1983). The intrinsic architectonic and connectional organization of the superior temporal region of the rhesus monkey. Journal of Comparative Neurology, 221, 169-184.

Gallagher, H. L., JACK, A. I., RoepstorfF, A., \& Frith, C. D. (2002). Imaging the intentional stance in a competitive game. NeuroImage, 16, 814-821

GhaZanfar, A. A., Maier, J. X., Hoffman, K. L., \& Logothetis, N. K. (2005). Multisensory integration of dynamic faces and voices in rhesus monkey auditory cortex. Journal of Neuroscience, 25, 5004-5012.

Ghazanfar, A. A., Turesson, H. K., Maier, J. X., van Dinther, R., Patterson, R. D., \& Logothetis, N. K. (2007). Vocal-tract resonances as indexical cues in rhesus monkeys. Current Biology, 17, 425-430.

Gothard, K. M., Battaglia, F. P., Erickson, C. A., Spitler, K. M., \& Amaral, D. G. (2007). Neural responses to facial expression and face identity in the monkey amygdala. Journal of Neurophysiology, 97, 1671-1683.

Grafman, J., Schwab, K., Warden, D., Pridgen, A., Brown, H. R., \& Salazar, A. M. (1996). Frontal lobe injuries, violence, and aggression: A report of the Vietnam Head Injury Study. Neurology, 46, 1231-1238.

Haber, S. N., Kim, K.-S., Mailly, P., \& Calzavara, R. (2006). Rewardrelated cortical inputs define a large striatal region in primates that interface with associative cortical connections, providing a substrate for incentive-based learning. Journal of Neuroscience, 26, 8368-8376.

Hadland, K. A., Rushworth, M. F. S., Gaffan, D., \& Passingham,
R. E. (2003). The effect of cingulate lesions on social behaviour and emotion. Neuropsychologia, 41, 919-931.

Harlow, J. (1848). Passage of an iron rod through the head. Boston Medical \& Surgical Journal, 39, 389-393.

HARLOW, J. (1868). Recovery from the passage of an iron bar through the head. Publications of the Massachusetts Medical Society, 2, 327347.

Heberlein, A. S., Padon, A. A., Gillihan, S. J., Farah, M. J., \& FelLows, L. K. (2008). Ventromedial frontal lobe plays a critical role in facial emotion recognition. Journal of Cognitive Neuroscience, 20, 721-733.

Hoffman, K. L., Gothard, K. M., Schmid, M. C., \& Logothetis, N. K. (2007). Facial-expression and gaze-selective responses in the monkey amygdala. Current Biology, 17, 766-772.

Hornak, J., Bramham, J., Rolls, E. T., Morris, R. G., O'Doherty, J., Bullock, P. R., \& Polkey, C. E. (2003). Changes in emotion after circumscribed surgical lesions of the orbitofrontal and cingulate cortices. Brain, 126, 1691-1712.

Hornak, J., O'Doherty, J., Bramham, J., Rolls, E. T., Morris, R. G., Bullock, P. R., \& Polkey, C. E. (2004). Reward-related reversal learning after surgical excisions in orbito-frontal or dorsolateral prefrontal cortex in humans. Journal of Cognitive Neuroscience, 16, 463478.

HornaK, J., Rolls, E. T., \& WadE, D. (1996). Face and voice expression identification in patients with emotional and behavioural changes following ventral frontal lobe damage. Neuropsychologia, 34, 247-261.

IVERSEN, S. D., \& MishKin, M. (1970). Perseverative interference in monkeys following selective lesions of the inferior prefrontal convexity. Experimental Brain Research, 11, 376-386.

IzQuierdo, A., SudA, R. K., \& Murray, E. A. (2004). Bilateral orbital prefrontal cortex lesions in rhesus monkeys disrupt choices guided by both reward value and reward contingency. Journal of Neuroscience, 24, 7540-7548.

Izquierdo, A., Suda, R. K., \& Murray, E. A. (2005). Comparison of the effects of bilateral orbital prefrontal cortex lesions and amygdala lesions on emotional responses in rhesus monkeys. Journal of Neuroscience, 25, 8534-8542.

Johansen-Berg, H., Gutman, D. A., Behrens, T. E. J., Matthews, P. M., Rushworth, M. F. S., Katz, E., ET AL. (2008). Anatomical connectivity of the subgenual cingulate region targeted with deep brain stimulation for treatment-resistant depression. Cerebral Cortex, 18, 1374-1383.

Kennedy, D. P., Redcay, E., \& Courchesne, E. (2006). Failing to deactivate: Resting functional abnormalities in autism. Proceedings of the National Academy of Sciences, 103, 8275-8280.

King-Casas, B., Tomlin, D., Anen, C., Camerer, C. F., Quartz, S. R., \& Montague, P. R. (2005). Getting to know you: Reputation and trust in a two-person economic exchange. Science, 308, 78-83.

Knutson, B., Fong, G. W., Adams, C. M., Varner, J. L., \& Hommer, D. (2001). Dissociation of reward anticipation and outcome with eventrelated fMRI. NeuroReport, 12, 3683-3687.

Koenigs, M., \& Tranel, D. (2007). Irrational economic decisionmaking after ventromedial prefrontal damage: Evidence from the Ultimatum Game. Journal of Neuroscience, 27, 951-956.

KoLB, B. (1974). Social behavior of rats with chronic prefrontal lesions. Journal of Comparative \& Physiological Psychology, 87, 466-474.

Kondo, H., SAleEM, K. S., \& Price, J. L. (2003). Differential connections of the temporal pole with the orbital and medial prefrontal networks in macaque monkeys. Journal of Comparative Neurology, $\mathbf{4 6 5}$, 499-523.

Kondo, H., Saleem, K. S., \& Price, J. L. (2005). Differential connections of the perirhinal and parahippocampal cortex with the orbital and medial prefrontal networks in macaque monkeys. Journal of Comparative Neurology, 493, 479-509.

Lacroix, L., Spinelli, S., Heidbreder, C. A., \& Feldon, J. (2000). Differential role of the medial and lateral prefrontal cortices in fear and anxiety. Behavioral Neuroscience, 114, 1119-1130.

Laplane, D., Degos, J. D., Baulac, M., \& Gray, F. (1981). Bilateral infarction of the anterior cingulate gyri and of the fornices: Report of a case. Journal of the Neurological Sciences, 51, 289-300.

Machado, C. J., \& Bachevalier, J. (2006). The impact of selective amygdala, orbital frontal cortex, or hippocampal formation lesions on 
established social relationships in rhesus monkeys (Macaca mulatta). Behavioral Neuroscience, 120, 761-786.

Machado, C. J., \& Bachevalier, J. (2007). The effects of selective amygdala, orbital frontal cortex or hippocampal formation lesions on reward assessment in nonhuman primates. European Journal of Neuroscience, 25, 2885-2904.

Macmillan, M. (2002). An odd kind of fame: Stories of Phineas Gage. Cambridge, MA: MIT Press.

Maia, T. V., \& McClelland, J. L. (2004). A reexamination of the evidence for the somatic marker hypothesis: What participants really know in the Iowa gambling task. Proceedings of the National Academy of Sciences, 101, 16075-16080.

Mayberg, H. S., Lozano, A. M., Voon, V., McNeely, H. E., Seminowicz, D., Hamani, C., ET AL. (2005). Deep brain stimulation for treatment-resistant depression. Neuron, 45, 651-660.

McClure, S. M., Ericson, K. M., Laibson, D. I., Loewenstein, G., \& Cohen, J. D. (2007). Time discounting for primary rewards. Journal of Neuroscience, 27, 5796-5804.

McClune, S. M., Laibson, D. I., Loewenstein, G., \& Cohen, J. D. (2004). Separate neural systems value immediate and delayed monetary rewards. Science, 306, 503-507.

McEnaney, K. W., \& Butter, C. M. (1969). Perseveration of responding and nonresponding in monkeys with orbital frontal ablations. Journal of Comparative \& Physiological Psychology, 68, 558-561.

McHugh, S. B., Deacon, R. M. J., Rawlins, J. N. P., \& Bannerman, D. M. (2004). Amygdala and ventral hippocampus contribute differentially to mechanisms of fear and anxiety. Behavioral Neuroscience, 118, 63-78.

Meunier, M., Bachevalier, J., Murray, E. A., Málková, L., \& MishKIN, M. (1999). Effects of aspiration versus neurotoxic lesions of the amygdala on emotional responses in monkeys. European Journal of Neuroscience, 11, 4403-4418.

MineKa, S., KeIR, R., \& Price, V. (1980). Fear of snakes in wild- and laboratory-reared rhesus monkeys (Macaca mulatta). Animal Learning \& Behavior, 8, 653-663.

Mitchell, J. P., Macrae, C. N., \& Banaji, M. R. (2004). Encodingspecific effects of social cognition on the neural correlates of subsequent memory. Journal of Neuroscience, 24, 4912-4917.

Mitchell, J. P., Macrae, C. N., \& BanaJi, M. R. (2006). Dissociable medial prefrontal contributions to judgments of similar and dissimilar others. Neuron, 50, 655-663.

Montague, P. R., \& Berns, G. S. (2002). Neural economics and the biological substrates of valuation. Neuron, 36, 265-284.

Moretti, L., Dragone, D., \& Di Pellegrino, G. (in press). Reward and social valuation deficits following ventromedial prefrontal damage. Journal of Cognitive Neuroscience.

Murray, E. A., \& IzQuierdo, A. (2007). Orbitofrontal cortex and amygdala contributions to affect and action in primates. In G. Schoenbaum, J. A. Gottfried, E. A. Murray, \& S. J. Ramus (Eds.), Linking affect to action: Critical contributions of the orbitofrontal cortex (Annals of the New York Academy of Sciences, Vol. 1121, pp. 273-296). New York: New York Academy of Sciences.

Murray, E. A., O’Doherty, J. P., \& Schoenbaum, G. (2007). What we know and do not know about the functions of the orbitofrontal cortex after 20 years of cross-species studies. Journal of Neuroscience, 27, 8166-8169.

Neary, D., Snowden, J. S., \& Mann, D. M. (2000). Classification and description of frontotemporal dementias. In J. Growdon, R. J. Wurtman, S. Corkin, \& R. M. Nitsch (Eds.), The molecular basis of dementia (Annals of the New York Academy of Sciences, Vol. 920, pp. 46-51). New York: New York Academy of Sciences.

Neary, D., Snowden, J. S., Northen, B., \& Goulding, P. (1988). Dementia of frontal lobe type. Journal of Neurology, Neurosurgery, \& Psychiatry, 51, 353-361.

OChSner, K. N., Beer, J. S., Robertson, E. R., CoOper, J. C., Gabrieli, J. D. E., Kinlstrom, J. F., \& D'Esposito, M. (2005). The neural correlates of direct and reflected self-knowledge. NeuroImage, 28, 797-814.

O'DoHeRTY, J. P. (2007). Lights, camembert, action! The role of human orbitofrontal cortex in encoding stimuli, rewards, and choices. In G. Schoenbaum, J. A. Gottfried, E. A. Murray, \& S. J. Ramus (Eds.), Linking affect to action: Critical contributions of the orbitofrontal cortex (Annals of the New York Academy of Sciences, Vol. 1121, pp. 254-272). New York: New York Academy of Sciences.
O'Doherty, J. [P.], Kringelbach, M. L., Rolls, E. T., Hornak, J., \& ANDREWs, C. (2001). Abstract reward and punishment representations in the human orbitofrontal cortex. Nature Neuroscience, 4, 95-102.

Ohnishi, T., Matsuda, H., Hashimoto, T., Kunihiro, T., NiShIKAWA, M., UEMA, T., \& SASAKI, M. (2000). Abnormal regional cerebral blood flow in childhood autism. Brain, 123, 1838-1844.

ÖNGÜR, D., AN, X., \& PRICE, J. L. (1998). Prefrontal cortical projections to the hypothalamus in macaque monkeys. Journal of Comparative Neurology, 401, 480-505.

ÖNGÜr, D., Drevets, W. C., \& Price, J. L. (1998). Glial reduction in the subgenual prefrontal cortex in mood disorders. Proceedings of the National Academy of Sciences, 95, 13290-13295.

Öngür, D., Ferry, A. T., \& Price, J. L. (2003). Architectonic subdivision of the human orbital and medial prefrontal cortex. Journal of Comparative Neurology, 460, 425-449.

PAdOA-Schioppa, C., \& Assad, J. A. (2006). Neurons in the orbitofrontal cortex encode economic value. Nature, 441, 223-226.

Plassmann, H., O'Doherty, J. [P.], \& Rangel, A. (2007). Orbitofrontal cortex encodes willingness to pay in everyday economic transactions. Journal of Neuroscience, 27, 9984-9988.

Poremba, A., Malloy, M., Saunders, R. C., Carson, R. E., HersCovitch, P., \& Mishinin, M. (2004). Species-specific calls evoke asymmetric activity in the monkey's temporal poles. Nature, $\mathbf{4 2 7}$, 448-451.

Price, J. L. (2005). Free will versus survival: Brain systems that underlie intrinsic constraints on behavior. Journal of Comparative Neurology, 493, 132-139.

Quirk, G. J., \& BeER, J. S. (2006). Prefrontal involvement in the regulation of emotion: Convergence of rat and human studies. Current Opinion in Neurobiology, 16, 723-727.

Quirk, G. J., Garcia, R., \& GonZÁlez-Lima, F. (2006). Prefrontal mechanisms in extinction of conditioned fear. Biological Psychiatry, 60, 337-343.

Ramnani, N., \& Owen, A. M. (2004). Anterior prefrontal cortex: Insights into function from anatomy and neuroimaging. Nature Reviews Neuroscience, 5, 184-194.

Rilling, J. K., Gutman, D. A., Zeh, T. R., Pagnoni, G., Berns, G. S., $\&$ KILTS, C. D. (2002). A neural basis for social cooperation. Neuron, 35, 395-405.

Rilling, J. K., Sanfey, A. G., Aronson, J. A., Nystrom, L. E., \& Cohen, J. D. (2004). The neural correlates of theory of mind within interpersonal interactions. Neurolmage, 22, 1694-1703.

RoBERTS, A. C. (2006). Primate orbitofrontal cortex and adaptive behaviour. Trends in Cognitive Sciences, 10, 83-90.

Roesch, M. R., \& Olson, C. R. (2004). Neuronal activity related to reward value and motivation in primate frontal cortex. Science, 304, 307-310.

Roesch, M. R., \& Olson, C. R. (2005). Neuronal activity in primate orbitofrontal cortex reflects the value of time. Journal of Neurophysiology, 94, 2457-2471.

Rolls, E. T. (1999). The brain and emotion. Oxford: Oxford University Press.

Rolls, E. T., Hornak, J., Wade, D., \& McGrath, J. (1994). Emotionrelated learning in patients with social and emotional changes associated with frontal lobe damage. Journal of Neurology, Neurosurgery, \& Psychiatry, 57, 1518-1524.

Rosen, H. J., Allison, S. C., Schauer, G. F., Gorno-Tempini, M. L., WeINER, M. W., \& MiLler, B. L. (2005). Neuroanatomical correlates of behavioural disorders in dementia. Brain, 128, 2612-2625.

Rudebeck, P. H., Buckley, M. J., Walton, M. E., \& Rushworth, M. F. S. (2006). A role for the macaque anterior cingulate gyrus in social valuation. Science, 313, 1310-1312.

Rudebeck, P. H., Walton, M. E., Millette, B. H. P., Shirley, E., Rushworth, M. F. S., \& Bannerman, D. M. (2007). Distinct contributions of frontal areas to emotion and social behaviour in the rat. European Journal of Neuroscience, 26, 2315-2326.

Rudebeck, P. H., Walton, M. E., Smyth, A. N., Bannerman, D. M., \& Rushworth, M. F. S. (2006). Separate neural pathways process different decision costs. Nature Neuroscience, 9, 1161-1168.

Saleem, K. S., Kondo, H., \& Price, J. L. (2008). Complementary circuits connecting the orbital and medial prefrontal networks with the temporal, insular, and opercular cortex in the macaque monkey. Journal of Comparative Neurology, 506, 659-693. 
Samson, D., Apperly, I. A., Chiavarino, C., \& Humphreys, G. W. (2004). Left temporoparietal junction is necessary for representing someone else's belief. Nature Neuroscience, 7, 499-500.

Sanfey, A. G., Rilling, J. K., Aronson, J. A., Nystrom, L. E., \& Cohen, J. D. (2003). The neural basis of economic decision-making in the Ultimatum Game. Science, 300, 1755-1758.

SAVER, J. L., \& DAmasio, A. R. (1991). Preserved access and processing of social knowledge in a patient with acquired sociopathy due to ventromedial frontal damage. Neuropsychologia, 29, 1241-1249.

Scearce-Levie, K., Roberson, E. D., Gerstein, H., Cholfin, J. A., Mandiyan, V. S., Shah, N. M., ET AL. (2008). Abnormal social behaviors in mice lacking Fgf17. Genes, Brain \& Behavior, 7, 344-354.

Schoenbaum, G., \& Roesch, M. (2005). Orbitofrontal cortex, associative learning, and expectancies. Neuron, 47, 633-636.

Schultz, W., Tremblay, L., \& Hollerman, J. R. (2000). Reward processing in primate orbitofrontal cortex and basal ganglia. Cerebral Cortex, 10, 272-283.

Seltzer, B., \& Pandya, D. N. (1978). Afferent cortical connections and architectonics of the superior temporal sulcus and surrounding cortex in the rhesus monkey. Brain Research, 149, 1-24.

Shah, A. A., \& Treit, D. (2003). Excitotoxic lesions of the medial prefrontal cortex attenuate fear responses in the elevated-plus maze, social interaction and shock probe burying tests. Brain Research, 969, 183-194.

Somerville, L. H., Heatherton, T. F., \& Kelley, W. M. (2006). Anterior cingulate cortex responds differentially to expectancy violation and social rejection. Nature Neuroscience, 9, 1007-1008.
Tanaka, S. C., Doya, K., Okada, G., Ueda, K., Okamoto, Y., \& YaMAWAKI, S. (2004). Prediction of immediate and future rewards differentially recruits cortico-basal ganglia loops. Nature Neuroscience, 7, 887-893.

Tomlin, D., Kayali, M. A., King-Casas, B., Anen, C., Camerer, C. F., Quartz, S. R., \& Montague, P. R. (2006). Agent-specific responses in the cingulate cortex during economic exchanges. Science, 312, 1047-1050.

Van Hoesen, G. W., Morecraft, R. J., \& Vogt, B. A. (1993). Connections of the monkey cingulate cortex. In B. A. Vogt \& M. Gabriel (Eds.), Neurobiology of the cingulate cortex and limbic thalamus: A comprehensive handbook (pp. 19-70). Boston: Birkhäuser.

Vogt, B. A., \& Peters, A. (1981). Form and distribution of neurons in rat cingulate cortex: Areas 32, 24, and 29. Journal of Comparative Neurology, 195, 603-625.

Wallis, J. D. (2007). Orbitofrontal cortex and its contribution to decision-making. Annual Review of Neuroscience, 30, 31-56.

WALlis, J. D., \& MiLler, E. K. (2003). Neuronal activity in primate dorsolateral and orbital prefrontal cortex during performance of a reward preference task. European Journal of Neuroscience, 18, 2069-2081.

Wheeler, E. Z., \& Fellows, L. K. (2008). The human ventromedial frontal lobe is critical for learning from negative feedback. Brain, 131, 1323-1331.

(Manuscript received March 19, 2008; revision accepted for publication July 20, 2008.) 